\title{
Effects of Eight Weeks of Aerobic Exercise on Markers of Oxidative Stress in Elderly Women
}

\author{
Mahdi Ghahremani Moghadam \\ (PhD) \\ Department of Exercise Physiology, \\ Faculty of Physical Education and \\ Sport Sciences, Ferdowsi University of \\ Mashhad, Mashhad, Iran \\ Keyvan Hejazi (PhD) \\ Department of Exercise Physiology, \\ Faculty of Physical Education and \\ Sport Sciences, Toos Institute of \\ Higher Education, Mashhad, Iran \\ Corresponding author: Mahdi \\ Ghahremani Moghadam \\ Email:m.ghahremani@um.ac.ir \\ Tel: +98-9155571102 \\ Address: Department of Exercise \\ Physiology, Faculty of Physical \\ Education and Sport Sciences, \\ Ferdowsi University of Mashhad, \\ Mashhad, Iran \\ Received : 28 Jan 2016 \\ Revised: 05 Jan 2016 \\ Accepted: 10 Aug 2016 \\ Mahdi Ghahremani Moghadam \\ https://orcid.org/0000-0003-4616-1478 \\ Keyvan Hejazi https://orcid.org/0000-0002-4590- \\ 8018
}

\section{ABSTRACT}

Background and Objectives: 0xidative stress is a common mediator in pathogenicity of established cardiovascular risk factors. The purpose of this study was to determine effects of selected aerobic training on some oxidative stress indicators in sedentary elderly women.

Methods: In this quasi-experimental study, 21 participants (age range: 60-70 years) were selected by convenience sampling and then randomly assigned to an exercise group $(n=11)$ and a control group $(n=10)$. Aerobic exercise was performed at $50-70 \%$ of heart rate reserve for 45-60 minutes per session, three sessions a week, for eight weeks. Blood samples were taken at baseline and 24 hours after the last training session. Within-group and between-group differences were assessed using paired sample t-test and independent t-test, respectively. Statistical significance level was set at 0.05 .

Results: Weight, body mass index and body fat percentage decreased significantly after the exercise intervention $(\mathrm{P}<0.05)$. We also noted a significant reduction in endothelin1 levels in both groups $(\mathrm{P}<0.05)$. Nitric oxide increased significantly after the eight-week exercise training $(\mathrm{P}<0.05)$. Moreover, serum 8-hydroxydeoxyguanosine levels decreased significantly in the exercise group $(\mathrm{P}<0.05)$. No significant change was observed in malondialdehyde and urinary 8-hydroxydeoxyguanosine levels in both groups. The result also showed a significant difference in subjects' weight and in nitric oxide and 8hydroxydeoxyguanosine levels between the two groups $(\mathrm{P}<0.05)$.

Conclusion: It seems that regular aerobic exercise at moderate intensity can improve antioxidative capacity and reduce the risk of cardiovascular disease in elderly women.

Keywords: Endothelin-1, 8-hydroxydeoxyguanosine, Exercise, Elderly. 


\section{INTRODUCTION}

Cardiovascular disease (CVD) is one of the most important causes of morbidity and mortality in developed countries (1). CVD is also the leading cause of death among individuals aged 65 years and over (2). Risk factors of CVD include increased blood pressure, increased blood cholesterol and sedentary lifestyle (3). Levels of malondialdehyde (MDA) (4), endothelin-1 (ET-1) (5), nitric oxide (NO) (6), 8hydroxydeoxyguanosine (8-OHdG) (7) and fibrinogen (8) are thought to be associated with the risk of CVD. MDA, a carbonyl group produced during lipid peroxidation and oxidative stress, is involved in detection of oxidative stress (9). Oxidative stress causes damage to these macromolecules and plays an essential role in the development of chronic diseases. In fact, free radicals in plasma attack the blood lipids and causes low density lipoprotein oxidation, resulting in hardening of the arterial walls and increased risk of atherosclerosis (10-11).

Vascular endothelial cells play an important role in the regulation of vascular function by producing vascular active substances, such as ET-1 (12-13). Of the two types of endothelial receptors present in humans, endothelin receptor type $\mathrm{A}$ is mostly found in heart and vascular smooth muscles, while the more extensively distributed endothelin receptor type B is found mainly in the kidney, uterus, the central nervous system and vascular endothelial cells. Endothelin receptor type A is crucial for the endothelin-mediated vasoconstriction, while endothelin receptor type B stimulates NO production (5). In addition, the endothelium produces numerous paracrine substances such as NO, which helps maintain the health of vascular wall and control vasomotor function. NO is an unstable and lipid soluble gas synthesized by endothelial cells through the activity of endothelial NO synthase (eNOS) (14). Exposure to reactive oxygen species significantly affects the structure of DNA, and plays a critical role in aging and development of atherosclerosis and diabetes (15). Moreover, 8 -OHdG has been recently considered as an indicator of oxidative DNA damage (7).

The positive effects of exercise and physical activity in the prevention of CVD have been proven (16). Implementing regular physical exercise in sedentary people improves risk factors of CVD (17). Several studies have shown that aerobic exercise can increase endothelium-dependent vasodilation in elderly healthy men (18). In addition, evidence supports the safety of moderate-intensity regular exercise for the elderly (4). Xiao et al. reported that regular aerobic exercise decreases ET, increases $\mathrm{NO}$ and reduces the ET/NO ratio (19). However, Boghrabadi et al. reported that aerobic exercise training causes a significant increase in ET-1 levels of young, middle-aged and old women (20). Radovanovic et al. showed that four weeks of pre-competition training had no effect on oxidative factors such as MDA and NO in 10 male judokas (mean age: $20 \pm 1.3$ years; sport experience: $11 \pm 3.4$ years) (21). On the other hand, Sacheck et al. showed that 12 weeks of downhill running for $45 \mathrm{~min}$ at $75 \%$ of maximum volume of oxygen $\left(\mathrm{VO}_{2} \max \right)$ increases serum concentrations of creatine kinase and MDA in healthy men (22).

Considering the important role of physical activity in the prevention and treatment of diseases, particularly CVD, performing exercise activities along with diet restrictions could improve vascular function. Moreover, exercise creates a sence of pleasure and satisfaction in people. Researchers have shown that tendency to perform physical activity reduces with age, and consequently, older people has a higher risk for CVD. Therefore, the present study aimed to study the effects of selected aerobic training on some indicators of oxidative stress in sedentary elderly women.

\section{MATERIAL AND METHODS}

This two-phased quasi-experimental study was performed to assess the effects of eight weeks of aerobic training in sedentary elderly women. The study received approval from the ethics committee of Ferdowsi University of Mashhad (code: 2.32123) and was conducted in accordance with the Helsinki Protocol. Twenty-one healthy volunteers aged $65.47 \pm 4.04$ years were selected via convenience sampling. In the first stage of the study, all volunteers completed a medical test as well as a medical questionnaire. None of the participants were taking any regular medication for the conditions such as cardiovascular, respiratory, renal and metabolic diseases. All procedures and exercise protocols were thoroughly explained 
to the participants. They had the right to withdraw from the study at any time. The participants were randomly assigned into an aerobic exercise group $(n=11)$ and a control group $(n=10)$. All the participants were healthy based on the medical records, personal information questionnaire and physical examination by a physician. Level of physical activity was assessed with the Kaiser Physical Activity Survey (KPAS). In the second stage of the study, the height of all participants was measured using a digital stadiometer (SECA, Germany) to the nearest $0.1 \mathrm{~cm}$. Weight was recorded using a digital scale (Beurer PS07, Germany). Waist-hip ratio was determined and bioimpedance parameters including body fat percentage, fat mass, and muscle mass and total body water were calculated using Inbody 720 Body Composition Analyzer (Biospace, Dogok-dong, South Korea). All the above measurements were done after four hours of fasting and on empty bladder and stomach.

The participants in the exercise group performed 45-60 minutes of aerobic training at $50-70 \%$ of maximum heart rate reserve (MHRR), three sessions a week, for eight weeks. The sessions usually started in the morning (9:30-11:00 AM) and all aerobic trainings were supervised by an experienced physical education instructor. Each session included a 10-min warm up (walking, stretching and movement exercise), $45 \mathrm{~min}$ specific training including walking/running at $50-70 \%$ of MHRR, and $10 \mathrm{~min}$ of cool down by jogging, walking and stretching (23). At the end of each session, all participants were examined and the exercise intensity was adjusted accordingly. The intensity of the trainings was controlled using the Borg scale. The control group did not participate in any physical activity during the study period. The MHRR for each participants was calculated based on the Karvonen formula (Target HR= $50 \%$ or $70 \% \times[(220$ - age $)$ - resting HR $]+$ resting HR), and was controlled during the training sessions with a heart rate monitor (Polar, Finland) (24). Fasting blood samples $(10 \mathrm{ml})$ were taken from the basilic vein 24 hours before the first training session and 24 hours after the last training session. All samples were taken between 8 and $10 \mathrm{AM}$ after a 15-min rest in a supine position. All participants were asked to avoid any intense physical activity such as cycling, running and walking for longer than $15 \mathrm{~min}$ before sampling. The samples were transferred to a tube containing K2EDTA and were mixed for $15 \mathrm{~min}$ before analysis. Serum was separated by centrifugation at $3000 \mathrm{rpm}$ for 10 minutes and was later stored at $-80{ }^{\circ} \mathrm{C}$ for subsequent analysis. Serum MDA and NO concentrations were determined using the photometric technique and ZellBio kits (Germany). ET-1 and $8-\mathrm{OHdG}$ levels were determined with ELISA using Cusabio kits (Japan). All samples were analyzed in duplicate. Statistical analysis was performed in SPSS (version 20) using descriptive statistics including means, standard deviation (SD) and standard error (SE). Normal distribution of the data was assessed using the Shapiro-Wilk test and the homogeneity of variances was tested by the Levene's test. Comparison of means within and between the groups was made using paired and independent sample t-test, respectively. Pvalue of less than 0.05 was considered statistically significant.

\section{RESULTS}

Main characteristics of the participants at baseline are shown in Table 1. After the exercise training, body weight, BMI and body fat percentage decreased significantly. No significant change in the working heart rate (WHR) was observed in the two groups (Table 2). At the end of the study, ET-1 level decreased significantly in both groups, while NO level increases significantly in the exercise group (Table 3).

Serum 8-OHdG level decreased significantly in the exercise group but did not change significantly in the control group. In addition, no significant change in the MDA level was observed in both groups after the eight-week training. The results also showed a significant difference in the weight and in the level of NO and 8-OHdG between the two groups $(\mathrm{P}<0.05)$. There was no significant difference in the intergroup mean values of BMI, body fat percentage, WHR, ET-1, MDA and urinary 8-OHdG levels.

Table 1- Main characteristics of the subjects at baseline

\begin{tabular}{|c|c|c|c|c|}
\hline \multirow[t]{2}{*}{ Groups } & \multicolumn{4}{|c|}{ Variables (Mean \pm SD) } \\
\hline & Age (year) & Height (cm) & Weight (Kg) & BMI $\left(\mathrm{Kg} / \mathrm{m}^{2}\right)$ \\
\hline Exercise $(n=11)$ & $64.36 \pm 4.12$ & $152.63 \pm 5.20$ & $68.60 \pm 10.40$ & $29.52 \pm 3.37$ \\
\hline Control $(n=10)$ & $66.70 \pm 3.77$ & $154.80 \pm 7.74$ & $71.70 \pm 10.40$ & $30.18 \pm 4.02$ \\
\hline
\end{tabular}


Table 2- Changes in the body composition of subjects in the two study groups

\begin{tabular}{|c|c|c|c|c|c|}
\hline \multirow[t]{2}{*}{ Variables } & \multirow[t]{2}{*}{ Groups } & \multicolumn{2}{|c|}{ Stage } & \multicolumn{2}{|c|}{ Difference } \\
\hline & & $\begin{array}{c}\text { Pre-test (Mean } \\
\text { 土 SD) }\end{array}$ & $\begin{array}{c}\text { Post-test (Mean } \pm \\
\text { SD) }\end{array}$ & P-Value* & P-Value** \\
\hline \multirow{2}{*}{$\begin{array}{l}\text { Weight } \\
\text { (Kg) }\end{array}$} & Exercise & $68.68 \pm 10.40$ & $67.40 \pm 10.20$ & $0.001 \dagger$ & $0.001 \uparrow$ \\
\hline & Control & $71.70 \pm 10.40$ & $72.10 \pm 9.80$ & 0.27 & \\
\hline BMI $\left(\mathrm{Kg} / \mathrm{m}^{2}\right)$ & $\begin{array}{l}\text { Exercise } \\
\text { Control }\end{array}$ & $\begin{array}{l}29.52 \pm 3.37 \\
30.18 \pm 4.02\end{array}$ & $\begin{array}{l}28.83 \pm 3.23 \\
30.13 \pm 3.93\end{array}$ & $\begin{array}{c}0.001 \dagger \\
0.84\end{array}$ & 0.06 \\
\hline Body fat & Exercise & $43.20 \pm 6.98$ & $41.36 \pm 7.24$ & $0.02 \div$ & 0.06 \\
\hline Percentage & Control & $41.51 \pm 6.35$ & $41.38 \pm 6.73$ & 0.80 & \\
\hline
\end{tabular}

Table 3- Changes in resting ET-1 levels and the indicators of oxidative stress in response to aerobic exercise

\begin{tabular}{|c|c|c|c|c|c|}
\hline \multirow[t]{2}{*}{ Variables } & \multirow[t]{2}{*}{ Groups } & \multicolumn{2}{|c|}{ Stages } & \multicolumn{2}{|c|}{ Difference } \\
\hline & & $\begin{array}{c}\text { Pre-test (Mean } \pm \\
\text { SD) }\end{array}$ & $\begin{array}{c}\text { Post-test (Mean } \pm \\
\text { SD) }\end{array}$ & P-Value* & P-Value*** \\
\hline \multirow[t]{2}{*}{ ET-1 (Pg/mL) } & Exercise & $3.42 \pm 1.39$ & $2.19 \pm 1.30$ & $0.005 \dagger$ & 0.347 \\
\hline & Control & $4.38 \pm 1.92$ & $2.58 \pm 1.18$ & $0.005 \dagger$ & \\
\hline \multirow[t]{2}{*}{$\mathrm{NO}(\mathrm{mm} / \mathrm{L})$} & Exercise & $3.34 \pm 0.25$ & $3.63 \pm 0.26$ & $0.006 \dagger$ & $0.046 \dagger$ \\
\hline & Control & $3.33 \pm 0.29$ & $3.40 \pm 0.34$ & 0.321 & \\
\hline \multirow[t]{2}{*}{$\operatorname{MDA}(\mathbf{m m} / \mathbf{L})$} & Exercise & $12.47 \pm 4.75$ & $12.27 \pm 2.71$ & 0.895 & 0.156 \\
\hline & Control & $22.09 \pm 14.42$ & $15.97 \pm 7.45$ & 0.124 & \\
\hline \multirow[t]{2}{*}{ Serum 8-OHdG (ng/mL) } & Exercise & $329.00 \pm 191.81$ & $271.00 \pm 143.34$ & $0.012 \dagger$ & $0.048 \dagger$ \\
\hline & Control & $366.20 \pm 146.92$ & $422.50 \pm 97.76$ & 0.273 & \\
\hline \multirow[t]{2}{*}{ Urinary 8-OHdG (ng/mL) } & Exercise & $8.14 \pm 4.17$ & $6.01 \pm 1.08$ & 0.118 & 0.305 \\
\hline & Control & $14.61 \pm 11.40$ & $13.16 \pm 9.23$ & 0.591 & \\
\hline
\end{tabular}

\section{DISCUSSION}

Regular aerobic exercise can reduce body composition and improve cardiovascular efficiency. In this study, the eight-week aerobic exercise had a significant impact on body weight, BMI and body fat percentage. This results is in line (25) but inconsistent (26) with the results of other studies. The inconsistency in the results could be due to the type of activity. For instance, fatty acids are the main fuel used by the muscles in aerobic training. The exercise regimen, daily physical activity, and intensity and duration of the training may also affect the outcome of training interventions.

We found that ET-1 level reduced significantly after the aerobic exercise intervention. This is in line with findings of Xiao-juan et al. (19) but inconsistent with findings of another study (27). Low concentration of ET-1 in blood may decrease the risk of heart diseases, hypertention, atherosclerosis and renal ischemia. Angiotensin II directly stimulates the production and release of norepinephrine as well as ET-1 in the endothelium, which results in severe contraction of the blood vessels. Recent studies reported that regular aerobic exercise significantly reduces angiotensin II levels that can consequently affect the production of ET-1 in endothelial cells (28). We also found that the eight-week aerobic exercise increases NO level, which is in line with some previous studies $(21,29,30)$. Shear stress also increases NO production via activation of ion channels, especially potassium channels (35), which itself activates receptor tyrosine kinase (36). The main source of NO production in the vascular endothelial cells is eNOS, which is activated during exercise and shear stress (37). The shear stress sensors in the vascular endothelial cells function through activity of several membrane-related molecules and pathways that could consequently activate NO production by eNOS $(38,39)$. The likely physiological stimulus for NO production is blood pressure regulation. Since regular exercise frequently increases pulse pressure, it can increase the bioavailability of NO (14). We noted a non-significant decrease in MDA levels after the eight-week aerobic exercise. The results of other studies in this regard have been inconsistent. For instance, Valadoa et al. 
reported an increase in $\mathrm{NO}$ and a decrease in MDA levels (40), while Shin Y et al. observed a significant increase in plasma levels of MDA after six months of aerobic exercise in women (41). Exercise can also increase generation of oxygen species, which might be due to increased oxygen consumption during physical activity. Hydroxyl radicals can cause lipid peroxidation, which leads to production of MDA (42). Regular aerobic exercise appears to improve anti-oxidative defense and reduce lipid and protein peroxidation (43). In fact, neutralization of free radicals results in improved antioxidative defense. Regular exercise increases the antioxidative capacity and protects the body against oxidative stressinduced damage (44).

In this study, 8-OHdG levels decreased significantly after the eight-week exercise intervention, which is in accordance with results of other studies $(45,46)$. However, Samia et al. reported that urinary level of 8OHdG increases significantly in professional female athletes during heptathlon race (47). Bloomer et al. reported no significant change in MDA or 8-OHdG levels after 30 minutes of continuous cycling at $70 \%$ of $\mathrm{VO}_{2} \max (48)$. Disparity in the results of the aforementioned studies may be due to difference in the duration and intensity of exercise and physical

\section{REFERENCES}

1. Buchan D, Ollis S, Thomas N, Baker J. The influence of a high intensity physical activity intervention on a selection of health related outcomes: an ecological approach. BMC Public Health. 2010;10:8.

2. North BJ, Sinclair DA. The intersection between aging and cardiovascular disease. Circulation research. 2012;110(8):1097-108.

3. Belmin J. Prevention of cardiovascular disease in elderly. Press Med. 2000;24:1234-9.

4. Jarrete A. Influence of aerobic exercise training on cardiovascular and endocrine-inflammatory biomarkers in hypertensive postmenopausal womenq. Journal of Clinical \& Translational Endocrinology. 2014;1:108e-14.

5. Qassemian A, Koushki Jahromi M. The effect of 12 weeks of intermittent aerobic exercise on endothelin-1 concentration of plasma in adult rats. Journal of Jahrom University of Medical Sciences, Vol 11, No 2, Summer 2013. 2013;11(2):1-6.

6. Oliveira V, Bessa A, Jorge M, R J, Oliveira S. The effect of different training programs on antioxidant status, oxidative stress, and metabolic control in type 2 diabetes. Appl Physiol Nutr Metab. 2012;37:334-44.

7. Powers SK, Jackson MJ. Exercise-induced oxidative stress: cellular mechanisms and impact on muscle force production. Physiol Rev. 2008 ;88(4):1243-76. fitness of the participants. Since $8-\mathrm{OHdG}$ is one of the main markers of oxidative DNA damage and an indicator of risk for CVD, reduction of 8 -OHdG following regular aerobic exercise at moderate intensity could be beneficial for reducing oxidative DNA damage and risk of CVD.

\section{CONCLUSION}

Eight weeks of periodic aerobic exercise exerts beneficial effects on cardiovascular risk factors by decreasing ET-1 and serum 8$\mathrm{OHdG}$ levels. It also causes a significant increase in NO levels. Therefore, it is recommended to perform regular aerobic exercise to reduce the risk of CVD, particularly in elderly women. A more comprehensive study should be performed on larger study populations to confirm our results.

\section{ACKNOWLEDGMENTS}

We would like to express our appreciation to the women participating in the study. This study has been supported by a grant from the Academy of Physical Education (code: 2.32123) at Ferdowsi University of Mashhad, Iran.

\section{CONFLICT OF INTEREST}

There is no conflict of interest to declare.

8. Markowe H, Marmot M, Shipley M, Bulpitt C, Meade T, Stirling Y, et al. Fibrinogen: a possible link between social class and coronary heart disease. British Medical Journal (Clinical Research Edition). 1985:1312-4.

9. Soydinç S, Çelik A, Demiryürek S. The relationship between oxidative stress, nitric oxide, and coronary artery disease. Eur J Gen Med. 2007;4(2):62-6.

10. Dekany M, Nemeskeri V, Györe I, Harbula I, Malomsoki J, Pucsok J. Antioxidant status of intervaltrained athletes in various sports. International journal of sports medicine. 2006;27(2):112-6.

11. Elosua R, Molina L, Fito M, Arquer A, SanchezQuesada J, Covas M, et al. Response of oxidative stress biomarkers to a 16-week aerobic physical activity program, and to acute physical activity, in healthy young men and women. Atherosclerosis. 2003;167(2):327-34.

12. Miyauchi T, Masaki T. Pathophysiology of endothelin in the cardiovascular system. Annu Rev Physiol. 1999;61:391-415.

13. Yanagisawa $M$, Kurihara $H$, Kimura $S$, Tomobe $Y$, Kobayashi M, Mitsui Y, et al. A novel potent vasoconstrictor peptide produced by vascular endothelial cells. Nature. 1988 Mar 31;332(6163):411-5.

14. Green D, Maiorana A, Driscoll G, Taylor R. Effect of exercise training on endothelium-derived nitric oxide function in humans. J Physiol. 2004;561(1):1-25. 
15. Wu LL, Chiou CC, Chang PY, Wu JT. Urinary 8OHdG: a marker of oxidative stress to DNA and a risk factor for cancer, atherosclerosis and diabetics. Clin Chim Acta. 2004 Jan;339(1-2):1-9.

16. De Bree A, Verschuren WM, Blom HJ, Kromhout D. Lifestyle factors and plasma homocysteine concentrations in a general population sample. American Journal of Epidemiology. 2001;154(2):150-4.

17. Kelley GA, Kelley KS. Efficacy of aerobic exercise on coronary heart disease risk factors. Prev Cardiol. 2008 Spring;11(2):71-5.

18. Gómez G, Jiménez R, Sánchez M. Epicatechin lowers blood pressure, restores endothelial function, and decreases oxidative stress and endothelin-1 and NADPH oxidase activity in DOCA-salt hypertension. Radical Bio Med 2012;52(1):70-9.

19.Xiao-juan S, Na H. About the effect of aerobic exercise to the endothelin and nitric oxide in cardiovascular system. Liaoning Sport Science and Technology. 2011;4:5-15.

20. Boghrabadi V, Hejazi Sm, Peeri M, Nejatpour S. The effect of Aerobic exercise training on endothelin-1 concentration in old women. Quarterly of Horizon of Medical Sciences. [Original]. 2012;17(4):70-7.

21. Radovanovic D, Stankovic N, Ponorac N, Nurkic M, Bratic M. Oxidative stress in young judokas: Effects of four week pre-competition training period. Science Of Martial Arts. 2012;8(3):147-51.

22. Sacheck JM, Milbury PE, Cannon JG, Roubenoff R, Blumberg JB. Effect of vitamin E and eccentric exercise on selected biomarkers of oxidative stress in young and elderly men. Free Radic Biol Med. 2003 Jun 15;34(12):1575-88.

23. Pollock ML, Wilmore J. Exercise in Health and Disease: Evaluation and Prescription for Prevention and Rehabilitation. 2 ed. WB Saunders: Philadelphia; 1990.

24. Robbert A, Landwehr R. The supporting history of the "HRmax=220-age" equation. Journal of Exercise Physiology online. 2002;5(2):1-10.

25. Pour-Abdi K, Shakerian S, Pour-Abdi Z, Janbozorgi M. Effects of Short-Term Interval Training Courses on Fitness and Weight Loss of Untrained Girls. Annals of Applied Sport Science. 2013;1(2):1-9.

26. Fakourian A, Azarbaijani M, Peeri M. Effect a period of selective military training on physical fitness, body mass index, mental health and mood in officer students. $\mathrm{J}$ Army Univ Med Sci. 2012;10(1):17-27.

27. Muratli HH, Çelebi L, Hapa O, Biçimoğlu A. Comparison of plasma endothelin levels between osteoporotic, osteopenic and normal subjects. BMC musculoskeletal disorders. 2005;6(1):49.

28. Taribiyan B, Baghaiee B, Attarzadeh Hosseini S. Effect of eight week moderate exercise training on Angiotensin Converting Enzyme gene expression and Angiotensin II activity in middle-aged men. Razi Journal of Medical Sciences. 2012;19(102):53-64.

29. Kazeem A, Olubayo A, Ganiyu A. Plasma Nitric Oxide and Acute Phase Proteins after Moderate and Prolonged exercises. Iran J Basic Med Sci. 2012 Jan;15(1):602-7.
30. Krause M, Rodrigues-Krause J, O'Hagan C, Medlow $\mathrm{P}$, Davison G, Susta D, et al. The effects of aerobic exercise training at two different intensities in obesity and type 2 diabetes: implications for oxidative stress, low-grade inflammation and nitric oxide production. European journal of applied physiology. 2014;114(2):251-60.

31. Hudlicka O, Brown MD. Adaptation of skeletal muscle microvasculature to increased or decreased blood flow: role of shear stress, nitric oxide and vascular endothelial growth factor. Journal of vascular research. 2008;46(5):504-12.

32. Van Royen N, Piek JJ, Buschmann I, Hoefer I, Voskuil M, Schaper W. Stimulation of arteriogenesis; a new concept for the treatment of arterial occlusive disease. Cardiovascular research. 2001;49(3):543-53.

33. Egginton S, Zhou A-L, Brown M, Hudlicka O. Unorthodox angiogenesis in skeletal muscle. Cardiovascular research. 2001;49(3):634-46.

34. Loufrani L, Henrion D. Role of the cytoskeleton in flow (shear stress)-induced dilation and remodeling in resistance arteries. Medical \& biological engineering \& computing. 2008;46(5):451-60.

35. Cunningham KS, Gotlieb AI. The role of shear stress in the pathogenesis of atherosclerosis. Laboratory investigation. 2005;85(1):9-23.

36. Lee HJ, Koh GY. Shear stress activates Tie2 receptor tyrosine kinase in human endothelial cells. Biochemical and biophysical research communications. 2003;304(2):399-404.

37. Higashi Y, Yoshizumi M. Exercise and endothelial function: role of endothelium-derived nitric oxide and oxidative stress in healthy subjects and hypertensive patients. Pharmacology \& therapeutics. 2004;102(1):8796.

38. Wei Q, Xia Y. Roles of 3-phosphoinositidedependent kinase 1 in the regulation of endothelial nitric-oxide synthase phosphorylation and function by heat shock protein 90. Journal of Biological Chemistry. 2005;280(18):18081-6.

39. Harrison D, Widder J, Grumbach I, Chen W, Weber M, Searles C. Endothelial mechanotransduction, nitric oxide and vascular inflammation. Journal of internal medicine. 2006;259(4):351-63.

40. Valadoa A, Tavaresb P, Pereirac L, Ribeiroa F. Anaerobic exercise and oxidative stress - Effect of the intense exercise on nitric oxide and malondialdehyde. Int Conference on Cellular \& Molecular Biology Biophysics \& Bioengineering; Greece2007. p. 26-8.

41. Shin Y-A, Lee J-H, Song W, Jun T-W. Exercise training improves the antioxidant enzyme activity with no changes of telomere length. Mechanisms of ageing and development. 2008;129(5):254-60.

42. Goldfarb AH, Bloomer RJ, McKenzie MJ. Combined antioxidant treatment effects on blood oxidative stress after eccentric exercise. Medicine and science in sports and exercise. 2005;37(2):234-9.

43. Polidori M, Mecocci P, Cherubini A, Senin U. Physical activity and oxidative stress during aging. International journal of sports medicine. 2000;21(3):1547. 


\section{3/ Ghahremani Moghadam and Hejazi}

44. Vincent H, Powers S, Stewart D, Shanely R, Demirel $\mathrm{H}$, Naito H. Obesity is associated with increased myocardial oxidative stress. Journal of the International Association for the Study of Obesity. 1999;23(1):67-74.

45. Rahimi R, Sharafi H. The Effect of a Bout of Resistance Exercise on 8-Hydroxy-2'-Deoxyguanosine in Athletes and Non-Athletes. Knowledge \& Health. 2012;7(1):1-7.

46. Revan S. Effects of acute high-intensity aerobic and anaerobic exercise on oxidative damage to lipids, proteins and DNA in untrained subjects. African Journal of Pharmacy and Pharmacology. 2011;5(10):1321-6.

47. Samia BAA, Youssef GA. Changes in Urinary 8Hydroxydeoxyguanosine Levels During Heptathlon Race in Professional Female Athletes. Journal of human kinetics. 2014;41(1):107-11.

48. Bloomer RJ, Goldfarb AH, Wideman L, McKenzie MJ, Consitt LA. Effects of acute aerobic and anaerobic exercise on blood markers of oxidative stress. The Journal of Strength \& Conditioning Research. 2005;19(2):276-85. 